\title{
AVALIAÇÃO DA EFICIÊNCIA DA APLICAÇÃO DE COAGULANTE ORGÂNICO EM CHORUME PARA REMOÇÃO
} DE CARGA ORGÂNICA E NUTRIENTES

\author{
Daniel Kuhn; Gustavo Reisdörfer*. \\ Centro de Ciências Exatas e Tecnológicas, Centro Universitário UNIVATES, Lajeado, RS, Brasil.
}

*E-mail: greisdorfer@univates.br

\section{RESUMO}

A proteção de mananciais e a preocupação com a escassez de água potável no mundo implicam, cada vez mais, na busca de alternativas que visem melhorar a eficiência dos sistemas de tratamento dos mais variados efluentes, difundindo parâmetros de operação. No caso dos lixiviados, ou chorume, de aterros sanitários, são consideradas variáveis importantes a idade de operação do aterro e as diferenças sazonais, principalmente em relação às condições climáticas e as peculiaridades de cada região, sendo que, dessa forma, não há um padrão para a operação de estações de tratamento, onde deve ser estudado caso a caso para um tratamento mais eficiente. Este estudo teve o objetivo de avaliar a eficiência do uso de coagulante orgânico no tratamento de chorume em jar-test, para posterior aplicação na planta da estação de tratamento, na etapa de decantação, avaliando a eficiência de remoção da demanda química de oxigênio (DQO), demanda biológica de oxigênio (DBO), nitrogênio total, turbidez além de avaliação do pH. Para DQO, obtevese um resultado médio de $30 \%$ de remoção, DBO $26 \%$ de remoção e para turbidez $84 \%$ de remoção. Para o parâmetro de nitrogênio total não houve eficiência de remoção. Conclui-se que essa etapa de coagulação pode ser acrescentada ao processo, com o propósito de remoção de carga orgânica, atuando como uma parte auxiliar no processo de tratamento.

Palavras-chave: aterro sanitário, chorume, coagulante.

\section{Introdução}

É comum definir lixo como sendo todo e qualquer resíduo que resulte das atividades diárias do homem na sociedade. A origem e formação do lixo urbano estão ligadas a fatores como variação sazonal, condições climáticas, hábitos e costumes, variações na economia entre outros. O lixo, disposto de maneira inadequada sem qualquer tratamento, pode poluir o solo, alterando suas características químicas, físicas e biológicas, constituindo-se em um problema de ordem estética e uma séria ameaça à saúde pública [1].

Existem alguns métodos para a disposição do lixo no solo, esses tendo que atender recomendações técnicas e sanitárias. O método mais viável atualmente no Brasil é a disposição do lixo em aterro sanitário. $\mathrm{O}$ aterro sanitário exige cuidados especiais e técnicas específicas a serem seguidas, que vão desde a seleção e preparo da área de sua instalação até sua operação e monitoramento. O objetivo principal de um aterro sanitário é dispor os resíduos no solo, de forma segura e controlada, garantindo a preservação do meio ambiente, a higiene e a saúde pública [2].

A decomposição anaeróbia dos resíduos depositados nos aterros sanitários, realizada por organismos que se alimentam de materiais orgânicos, somado a água da chuva que penetra no aterro, resulta em um líquido denominado lixiviado ou chorume [3].

Um gerenciamento e tratamento inadequado do chorume ocasiona impacto ao meio ambiente, podendo contaminar águas superficiais e subterrâneas. As características do chorume mudam ao longo do tempo em função da fase em que o aterro se encontra. Quanto mais novo for o aterro mais ácido será o chorume, chamada de fase ácida (popularmente conhecido como chorume novo), apresentando grandes concentrações de ácidos voláteis, elevada carga orgânica, $\mathrm{pH}$ baixo e a microbiota metanogênica sem tempo de se desenvolver. Quando o aterro já está com um volume de resíduo mais expressivo, essa fase é chamada de metanogênica (popularmente chamado de chorume velho). Com a microbiota bem desenvolvida, ela consome os ácidos voláteis e os converte em gás carbônico e metano, apresentando dessa forma carga orgânica mais baixa, $\mathrm{pH}$ elevado e significativas concentrações de nitrogênio amoniacal [4].

Mesmo depois de encerrado, um aterro sanitário continua gerando chorume durante vários anos. Esse chorume é cada vez menos biodegradável, necessitando para o seu tratamento processos mais complexos ou a inserção de novos processos [5].

Devido às peculiaridades e diversidades das características de lixiviados, levando em conta as diferenças sazonais, principalmente em relação às condições climáticas de cada região, muitas pesquisas são realizadas continuamente, adaptando sistemas e processos à realidade local, permitindo chegar a diversas opções possíveis para a redução de cargas orgânicas presentes no chorume gerado em aterros sanitários [6]. O tratamento do lixiviado através de sistemas biológicos e aeróbios é bastante efetivo quando o lixiviado é novo e quando a razão DBO/DQO é maior que a 0,4. Mas o tratamento biológico isoladamente pode ser ineficiente quando o lixiviado é originário de aterros de meia-idade e 
velho. Neste caso, o efluente apresenta uma resistência à biodegradação e necessita de um tratamento que diminua a sua recalcitrância [7].

O tratamento de lixiviados por processos físico-químicos constitui-se em uma etapa primordial na busca de diminuição da carga poluente destes efluentes. A degradação ou separação dos componentes orgânicos no lixiviado depende da composição química dos compostos orgânicos presentes (estrutura e peso molecular) e das condições ambientais que podem modificá-los. Para isso, são vários os processos de tratamento possíveis, dentre eles a coagulação/floculação [8].

Os coagulantes orgânicos apresentam várias vantagens em relação aos coagulantes inorgânicos por serem biodegradáveis e nãotóxicos, e ainda produzirem lodo em menor quantidade e isento de sais metálicos, o que facilita a sua compostagem e disposição final [9]. Os coagulantes orgânicos atualmente utilizados atuam em sistemas de partículas coloidais, neutralizando cargas e formando pontes entre estas partículas, sendo este processo responsável pela formação de flocos e consequente sedimentação [10].

O objetivo desse estudo foi o de avaliar a eficiência de remoção de DQO, DBO, turbidez e nitrogênio total, através de um tratamento físico-químico em jar-test, com o coagulante orgânico catiônico, em efluente gerado no aterro sanitário de Lajeado, RS.

\section{Parte Experimental}

\subsection{Estação de tratamento do aterro sanitário de Lajeado/RS}

A coleta de chorume é feita através de dutos que transferem o líquido à estação de tratamento de efluentes (ETE) por diferença de gravidade. Primeiramente, o chorume chega à calha Parshall. Após, o lixiviado deságua em uma lagoa anaeróbia, posteriormente sendo transferida para uma lagoa aeróbia. $\mathrm{O}$ efluente então passa para o decantador secundário que separa a parte mais grosseira do lodo, retornando este para a lagoa de aeração e transferindo o efluente clarificado para tanque de acúmulo. Do tanque de acúmulo o efluente é bombeado para o sistema de microfiltração para que fiquem retidas partículas dos sólidos que possivelmente tenham remanescido no efluente. Na sequência passa por um filtro catalítico para remoção de metais e então segue para o tratamento com ozônio, para remover a cor, odor e microrganismos do efluente, passando assim para o corpo hídrico receptor das águas tratadas do aterro sanitário de Lajeado.

\subsection{Amostragem e reagente}

As amostras do efluente analisado foram obtidas ao longo do mês de outubro de 2014. Foram coletadas 3 amostras, por três semanas consecutivas. As amostras foram coletadas na superfície da lagoa aeróbia da estação. Primeiramente, foram aplicadas 5 dosagens diferentes de coagulante orgânico catiônico em jar-test: $0,5 \mathrm{~mL} / \mathrm{L}, 1,0 \mathrm{~mL} / \mathrm{L}, 1,5 \mathrm{~mL} / \mathrm{L}$, 2,0 mL/L e 2,5 mL/L. Essa diferenciação de dosagem teve por objetivo verificar a dosagem ideal à ser aplicada nas demais amostras para melhor rendimento, e teve como base estudos realizados por outros autores em diferentes aterros sanitários utilizando o mesmo coagulante orgânico. A escolha da dosagem ideal se deu pela avaliação da turbidez do efluente tratado.

\subsection{Análise do efluente}

Para caracterizar e demonstrar a eficiência do tratamento proposto, foram realizadas análises de $\mathrm{pH}$, turbidez, nitrogênio total, DQO e DBO antes e após o tratamento.

\subsubsection{Determinação de $p H$}

As amostras foram homogeneizadas e submetidas à leitura em temperatura de $25 \pm 1{ }^{\circ} \mathrm{C}$. O aparelho utilizado foi o modelo $\mathrm{pH}-2000 \mathrm{da}$ marca Instrutherm.

\subsubsection{Determinação de Turbidez.}

As amostras foram homogeneizadas e submetidas à leitura em um turbidímetro, que opera com o princípio nefelométrico. O método é baseado na comparação da intensidade de luz espalhada pela amostra em condições definidas, com a intensidade da luz espalhada por uma suspensão considerada padrão.

\subsubsection{Determinação de Nitrogênio Total}

Procede-se na amostra previamente preparada a digestão, a destilação e a titulação com ácido sulfúrico, medindo-se o nitrogênio total Kjeldahl (NTK) [11].

\subsubsection{Determinação de $\mathrm{DBO}$}

O método consiste em encher com a amostra diluída até transbordar um frasco hermeticamente fechado de tamanho específico e incubá-lo à temperatura especificada durante 5 dias. O oxigênio dissolvido é medido inicialmente e após a incubação, e a DBO é calculada a partir da diferença entre o oxigênio dissolvido inicial e final [12].

\subsubsection{Determinação de $D Q O$}

A maioria dos tipos de matéria orgânica é oxidada por uma mistura em ebulição de cromo e ácido sulfúrico. Uma amostra é submetida a refluxo em solução fortemente ácida com um excesso conhecido de dicromato de potássio $\left(\mathrm{K}_{2} \mathrm{Cr}_{2} \mathrm{O}_{7}\right)$. Depois da digestão, o dicromato de potássio não reduzido remanescente é titulado com sulfato de amônio ferroso para determinar a quantidade de dicromato de potássio consumido e a matéria oxidável é calculada em termos de oxigênio equivalente [13].

\section{Resultados e discussões}

\subsection{Caracterização do chorume bruto}

A caracterização do efluente bruto do aterro sanitário de Lajeado/RS foi realizada através da análise dos laudos de monitoramento do efluente, com amostras coletadas na calha Parshall, referentes ao monitoramento mensal realizado em 2013, nos parâmetros de pH, nitrogênio total, $\mathrm{DBO}$ e $\mathrm{DQO}$, a fim de identificar a fase em que se 
encontra o chorume a ser tratado através da relação DBO/DQO, como pode ser observado na tabela 1 .

Tabela 1: Caracterização efluente bruto no ano de 2013.

\begin{tabular}{ccccc}
\hline Parâmetro & Unidade & Mínimo & Máximo & Média \\
\hline DBO & $\mathrm{mg} / \mathrm{L}$ & 424 & 1530 & 786 \\
DQO & $\mathrm{mg} / \mathrm{L}$ & 1398 & 2927 & 1957 \\
NTK & $\mathrm{mg} / \mathrm{L}$ & 289 & 925 & 651 \\
pH & & 5,7 & 8,8 & 7,9 \\
DBO/DQO & & 0,2 & 0,5 & 0,4 \\
\hline
\end{tabular}

De acordo com a tabela 1, pode-se verificar que o valor médio de pH encontrado é levemente alcalino. Segundo Calijuri e Cunha [4] e de acordo com os valores de $\mathrm{pH}$ observados, o lixiviado se encontra numa fase metanogênica, com valores de $\mathrm{pH}$ alcalinos, e não numa fase ácida, caracterizada por valores de $\mathrm{pH}$ menores. Nesta fase metanogênica há a decomposição dos produtos de fermentação ácida que são convertidos em metano $\left(\mathrm{CH}_{4}\right)$, substâncias húmicas e água. Segundo Ferreira et al. [7], a relação DBO/DQO sendo 0,4 indica um lixiviado de aterro de meia idade, implicando em um tratamento mais complexo.

\subsection{Ensaio de coagulação/floculação}

A avaliação da melhor dosagem de coagulante a ser utilizada foi obtida ao adicionar diferentes volumes à amostra e verificar qual o melhor percentual de remoção referente ao parâmetro de turbidez, no experimento realizado em jar-test. A turbidez mostrou-se um parâmetro importante na indicação do desempenho do coagulante pois a sua redução indica a remoção dos sólidos em suspensão no lixiviado. O melhor resultado foi obtido utilizando $2 \mathrm{~mL} / \mathrm{L}$ de coagulante, com $81 \%$ de remoção de turbidez, como pode ser observado na tabela 2.

\begin{tabular}{ccccccc}
\multicolumn{7}{l}{ Tabela 2: resultado do ensaio com diferentes dosagens de coagulante. } \\
\hline Parâmetro & Bruto & $\begin{array}{c}0,5 \\
\mathrm{~mL} / \mathrm{L}\end{array}$ & $\begin{array}{c}1 \\
\mathrm{~mL} / \mathrm{L}\end{array}$ & $\begin{array}{c}1,5 \\
\mathrm{~mL} / \mathrm{L}\end{array}$ & $\begin{array}{c}2,0 \\
\mathrm{~mL} / \mathrm{L}\end{array}$ & $\begin{array}{c}2,5 \\
\mathrm{~mL} / \mathrm{L}\end{array}$ \\
\hline $\begin{array}{c}\text { Turbidez } \\
\text { (NTU) } \\
\% \text { de } \\
\text { remoção }\end{array}$ & 12,1 & 43,5 & 21,9 & 3,5 & 2,3 & 3,7 \\
$\mathrm{pH}$ & 7,6 & 7,2 & 6,9 & 6,6 & 5,7 & 4,8 \\
\hline
\end{tabular}

*Não houve remoção.

No trabalho de Bassani [14], na avaliação da tratabilidade de lixiviado do aterro de Maringá, no Paraná, com a utilização de coagulantes orgânicos, a dosagem ideal foi de $30 \mathrm{~mL} / \mathrm{L}$, utilizando o coagulante com diluição de $10 \%$ (v/v), sendo um volume de dosagem semelhante ao encontrado neste trabalho, uma vez que para o mesmo não houve diluição do coagulante. Para Máximo [15], em seu trabalho no tratamento por coagulação-floculação dos lixiviados do aterro sanitário da região metropolitana de Florianópolis, encontrou uma dosagem ideal de coagulante orgânico, também diluído a 10\% (v/v), de 2000 mg/L obtendo uma remoção de turbidez de $67 \%$. Essa comparação reforça a importância do estudo caso a caso, levando em conta a singularidade dos lixiviados em diferentes aterros sanitários. O acompanhamento do parâmetro de turbidez é importante, tendo em vista que a elevada turbidez provoca atenuação de luz no meio aquoso e compromete e metabolismo dos organismos fotossintetizantes, e ainda, que a mesma pode ser influenciada pelo tipo de tratamento adotado, como pode ser observado no tratamento proposto com 0,5 mL/L e $1 \mathrm{~mL} / \mathrm{L}$, onde ocorreu um aumento de turbidez.

Observa-se uma diminuição de $\mathrm{pH}$ conforme o aumento de adição de coagulante, pois o coagulante é comercializado numa faixa de $\mathrm{pH}$ entre 1,3 e 2,3, sendo efetivo numa faixa de $\mathrm{pH}$ de 4,5 a $8 . \mathrm{O} \mathrm{pH}$ resultante após a aplicação do coagulante na dosagem ideal ficou abaixo do mínimo estabelecido pela legislação, o que indica a necessidade de uma etapa posterior de tratamento para a padronização deste parâmetro.

\subsection{Eficiência na remoção de carga orgânica e nutrientes}

A Tabela 3 apresenta os resultados médios para os parâmetros determinados, utilizando como padrão a dosagem de $2 \mathrm{~mL} / \mathrm{L}$ de coagulante no chorume. Pode-se observar remoção após o tratamento com coagulante nos parâmetros de DBO, DQO e turbidez. Para o parâmetro de nitrogênio total não houve remoção, podendo ser observado uma concentração maior desse parâmetro na amostra após o tratamento.

Como demonstrado na figura 1 , obteve-se uma média de remoção de $26 \%, 30 \%$ e $84 \%$ para $\mathrm{DBO}$, DQO e turbidez, respectivamente.

Figura 1- Gráfico com os percentuais de remoção

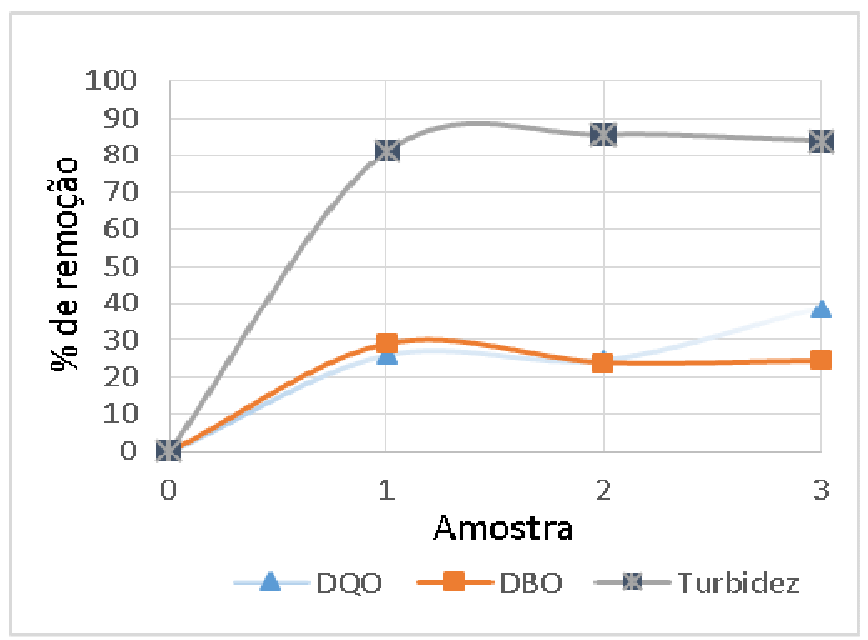

Bassani [14], não obteve remoção de DQO utilizando o mesmo coagulante orgânico utilizado neste trabalho, e sim um aumento dos valores à medida que aumentava a dosagem no tratamento. Máximo [15], utilizando coagulante a base de tanino atingiu $38 \%$ de remoção. Amokrane et al. [16], utilizando cloreto férrico, obteve remoção entre 42 e $55 \%$. Nota-se que mesmo com o uso de coagulantes inorgânicos a eficiência de remoção não se apresentou muito elevada.

Percebe-se que os resultados apresentados para remoção de DBO e DQO, com a utilização de diferentes coagulantes, sejam orgânicos ou inorgânicos, geralmente não apresentam elevadas eficiências de remoção. 
Tabela 3 - Valores médios para DBO, DQO, turbidez, nitrogênio total (NTK) e pH.

\begin{tabular}{|c|c|c|c|c|c|c|c|c|c|c|c|c|c|c|}
\hline \multirow[b]{2}{*}{ Amostra } & \multicolumn{2}{|c|}{$\begin{array}{c}\text { DQO } \\
(\mathrm{mg} / \mathrm{L})\end{array}$} & \multirow[t]{2}{*}{$\begin{array}{c}\text { Eficiência } \\
(\%)\end{array}$} & \multicolumn{2}{|c|}{$\begin{array}{c}\text { DBO } \\
(\mathrm{mg} / \mathrm{L})\end{array}$} & \multirow[t]{2}{*}{$\begin{array}{c}\text { Eficiência } \\
(\%)\end{array}$} & \multicolumn{2}{|c|}{$\begin{array}{c}\text { Turbidez } \\
\text { (NTU) }\end{array}$} & \multirow[t]{2}{*}{$\begin{array}{c}\text { Eficiência } \\
(\%)\end{array}$} & \multicolumn{2}{|c|}{$\begin{array}{c}\text { NTK } \\
(\mathrm{mg} / \mathrm{L})\end{array}$} & \multirow[t]{2}{*}{$\begin{array}{c}\text { Eficiência } \\
(\%)\end{array}$} & \multicolumn{2}{|c|}{ pH } \\
\hline & $\mathrm{B}^{*}$ & $\mathrm{~T}^{* *}$ & & $\mathrm{~B}^{*}$ & $\mathrm{~T}^{* *}$ & & $\mathrm{~B}^{*}$ & $\mathrm{~T}^{* *}$ & & $\mathrm{~B}^{*}$ & $\mathrm{~T}^{* *}$ & & $\mathrm{~B}^{*}$ & $\mathrm{~T}^{* *}$ \\
\hline Amostra 1 & 469,7 & 348,5 & 25,8 & 181,4 & 128,9 & 28,9 & 12,1 & 2,3 & 81,0 & 10,2 & 11,3 & $-10,8$ & 8,0 & 5,7 \\
\hline Amostra 2 & 600,8 & 453,5 & 24,5 & 230,8 & 175,6 & 23,9 & 16,8 & 2,4 & 85,7 & 9,0 & 10,4 & $-15,6$ & 8,0 & 5,7 \\
\hline
\end{tabular}

$\mathrm{B}^{*}$ : efluente sem tratamento; $\mathrm{T}^{* *}$ : efluente após tratamento.

Amokrane et al. [16] sugere que o processo de coagulação seja fortemente influenciado pelo $\mathrm{pH}$. Felici et al. [17], em seu trabalho de remoção de carga orgânica recalcitrante de lixiviado de resíduos sólidos urbanos, prétratados biologicamente por coagulação química-floculaçãosedimentação, utilizando cloreto férrico, obteve significativa evolução na eficiência de remoção de DQO com pH 3, removendo $81 \%$ de DQO, contra 54\% de remoção de DQO com pH 6. Segundo Castro [18], a influência do $\mathrm{pH}$ na eficiência de remoção da DQO pode ser explicada pelo fato de que a coagulação química ser altamente dependente do parâmetro, bem como agir diretamente sobre a dissolução do metal coagulante. Aziz et al. [19] estudou a influência do pH, efetuando testes com pH entre 2 e 14, com e sem a adição de coagulante, investigando a remoção de cor. Os resultados mostraram que o lixiviado passou de uma cor escura para uma cor marrom claro em valores de $\mathrm{pH}$ mais baixos e mais altos, e Felici et al. [17] observou que houve uma relação de eficiência do tratamento entre cor e DQO, onde a maior remoção de cor resultou em uma maior remoção de DQO, sugerindo que os altos teores desses parâmetros encontrados no lixiviado devam ser causados pela mesma fonte, como as substâncias húmicas.

Nagashima [20] obteve condição ótima de operação com coagulante orgânico em um pH de 7,4. Em uma comparação entre pH $4 \mathrm{e}$ 9, para tratamento de chorume com coagulante orgânico, Pedroso [21] obteve melhor resultado de remoção para o parâmetro de turbidez utilizando $\mathrm{pH}$ 9. Conforme se pode constatar na tabela $3, \mathrm{o} \mathrm{pH}$ variou em torno de 8,0, sendo que não foram realizados quaisquer ajustes para a aplicação do tratamento.

Para o parâmetro de nitrogênio total Kjeldahl, não houve remoção, mas sim uma concentração média de $12,4 \%$ na amostra tratada. Segundo Sedlak [22], o nitrogênio pode ser encontrado em diversas formas no meio aquático, devido aos estados de oxidação que pode assumir, como: nitrogênio molecular $\left(\mathrm{N}_{2}\right)$, escapando para a atmosfera; nitrogênio orgânico, que pode estar dissolvido ou em suspensão; nitrogênio amoniacal $\left(\mathrm{NH}_{3} / \mathrm{NH}^{4+}\right)$; nitrito $\left(\mathrm{NO}^{2-}\right)$ e nitrato $\left(\mathrm{NO}^{3-}\right)$.
A remoção do nitrogênio de lixiviados apresenta melhores rendimentos quando realizado por processos biológicos ou por processo de stripping. $\mathrm{O}$ fato de não ter obtido remoção para esse parâmetro não implica em uma complicação, uma vez que o valor encontrado atende a resolução CONSEMA n ${ }^{\circ}$ 128/2006 [23].

\section{Conclusões}

O processo de coagulação/floculação obteve um resultado abaixo do esperado, porém satisfatório em virtude da complexidade do tratamento dos lixiviados provenientes do aterro sanitário, para remoção de carga orgânica. Quanto à redução de nutrientes mostrou-se ineficaz.

Os melhores resultados ficaram a cargo da turbidez do efluente tratado, tendo em vista que a remoção em chorume exige geralmente processos mais avançados.

Como sugestão para trabalhos futuros, sugere-se a avaliação do comportamento do sistema em relação ao $\mathrm{pH}$.

Quanto a remoção de carga orgânica, expressa em termos de $\mathrm{DBO}$ e DQO, as eficiências apresentaram-se baixas, porém semelhantes à de outros trabalhos que também avaliaram o processo de coagulação/floculação com o uso de coagulante orgânico.

Vale ressaltar que um grande benefício na utilização de coagulantes orgânicos em tratamentos de diferentes efluentes com geração de lodo, é o de que não há acréscimo de metal no lodo gerado, proveniente do coagulante utilizado, podendo o mesmo ser recirculado novamente na célula do aterro para ser biodegradado, sem a incorporação de resíduos que dificultem o tratamento posterior dos lixiviados gerados.

Esse é um processo que pode ser utilizado como complemento do tratamento já existente, uma vez que empregado em conjunto com sistema de ozonização existente no aterro, pode obter resultados mais satisfatórios. 


\section{EVALUATION OF THE EFFICIENCY OF APPLICATION OF ORGANIC COAGULANT ON MANURE FOR REMOVAL OF ORGANIC LOAD AND NUTRIENTS}

\begin{abstract}
The protection of fountains and the concern around the shortage of clean water in the world imply, more and more each day, in the search of alternatives that will improve the efficiency of treatment of various effluents, propagating operating parameters. In the case of leachate, or manure, of landfills, important variables considered are the operating age of the landfill and the seasonal differences, especially in regards to the weather conditions and the peculiarities of each region. There by there is no pattern for the treatment plants operation and each case should be studied for a more effective treatment. This study evaluated the efficiency in the use of organic coagulant in the treatment of manure in jar-test, for posterior application in the treatment plant, in the decantation stage, evaluating the efficiency in the removal of chemical oxygen demand (COD), biological oxygen demand (BOD), total nitrogen, turbidity and $\mathrm{pH}$ analysis. For the COD, the average result was $30 \%$ of removal, BOD $26 \%$ of removal and for turbidity $84 \%$ of removal. For the total nitrogen parameter there was no efficiency in the removal. In conclusion, this stage of coagulation may be added to the process for the purpose of removal of the organic load, acting as an auxiliary part in the treatment process.
\end{abstract}

Key-words: Landfill. Manure. Coagulant.

\section{Referências}

[1] LIMA, L.M.Q. LIXO, tratamento e biorremediação, $3^{\text {a }}$ edição, São Paulo: Hemus, 2004.

[2] LIMA, J. D. Gestão de resíduos sólidos urbanos no Brasil, Editora EMLUR, 2001.

[3] MEIRA, José Carlos Rodrigues. Chorume do Aterro Sanitário de Goiânia: Tratamento por Floculação/Coagulação/degradação Fotoquímica e Custos operacionais. Dissertação de Mestrado. UFSC, Florianópolis, SC, 2003.

[4] CALIJURI, M.C. e CUNHA, D.G.F. Engenharia Ambiental: conceitos, tecnologia e gestão. Rio de Janeiro: Elsevier, 789p. 2013

[5] SILVA, Alessandra Cristina. Tratamento de Percolado de Aterro Sanitário e Avaliação da Toxicidade. Tese (programa de pós-graduação - Mestrado) COOPE/UFRJ, Rio de Janeiro, RJ, Brasil, 2002.

[6] MORAIS, Josmaria Lopes. Estudo da potencialidade de processos oxidativos avançados, isolados e integrados com processos biológicos tradicionais, para tratamento de lixiviado de aterro sanitário. Tese (Doutorado em química), Universidade Federal do Paraná. Curitiba, PR, 2005.
[7] FERREIRA, J. A. GIORDANO, G.; RITTER, E.; ROSSO, TCA; CAMPOS, JC; LIMA PZM. Uma revisão das técnicas de tratamento de chorume e a realidade do estado do Rio de Janeiro. In: Anais do $21^{\circ}$ Congresso Brasileiro de Engenharia Sanitária e Ambiental, João Pessoa, 2001.

[8] BAIG, S.; COULOMB, I; COURANT, P.; LIECHTI, P. Treatment of landfill leachates: lapeyrouse and satrod case studies", Ozone Science \& Engineering, vol. 21, pp. 1-22, 1999.

[9] KAWAMURA, S. Effectiveness of natural polyelectrolytes in water treatment. Journal American Water Works Association, v. 83, n. 10, p. 88-91, 1991.

[10] GRAHAM, N.; GANG, F.; FOWLER, G.; WATTS, M. Characterization and coagulation performance of a tannin based cationic polymer: a preliminary assessment. Colloids and Surface A: Physicochemical and Engineering Aspects, v. 327, n. 1-3, p. 9-16, 2008.

[11] STANDART METHODS, For the Examination of Water and Wastewater, method 4500 NB. Macro-Kjeldahl Method p. 4-132,22 $2^{\text {st }}$ edition, 2012.

[12] STANDART METHODS, For the Examination of Water and Wastewater, method 5210 B. p. $5-5,22^{\text {st }}$ edition, 2012.

[13] STANDART METHODS, For the Examination of Water and Wastewater, method 5220 B.p. $5-17,22^{\text {st }}$ edition, 2012 .

[14] BASSANI, Fabiana. Monitoramento do lixiviado do aterro controlado de Maringá, Paraná, e avaliação da tratabilidade com coagulantes naturais, radiação ultravioleta (UV) e ozônio. Tese (Dissertação Pós-graduação) Universidade Estadual de Maringá, PR, 2010.

[15] MÁXIMO, Vivian Alves. Tratamento por coagulação-floculação dos lixiviados do aterro sanitário da região metropolitana de Florianópolis. Tese (Doutorado). Departamento de Engenharia Ambiental, Universidade Federal de Santa Catarina. Florianópolis, SC, 2007.

[16] AMORRANE. A, COMEL, C., VERON, J., Landfill leachates pretreatment by coagulation-flocculation. Wat. Res. Vol.31, n¹1, p. 2775-2782, 1997.

[17] FELICI. E.M., KURODA, E. K., YAMASHITA, F., SILVA, S.M.C.P. Remoção de carga orgânica recalcitrante de lixiviado de resíduos sólidos urbanos pré-tratado biologicamente por coagulação química-floculação-sedimentação. Eng. Sanit. Ambient. Vol. 18, n². Rio de Janeiro Abril/junho 2013.

[18] CASTRO, A.P., YAMASHITA, F., SILVA, S.M.C.P. Adição de polieletrólito ao processo de floculação no pós-tratamento de lixiviado por coagulação-floculação-sedimentação. Eng. Sanit. Ambient, v. 17 n.1, p25-32, jan/mar 2012

[18] AZIZ, H.A.; ALIAS, S.; ADLAN, M.N.; FARIDAH, A.H.; ZAHARI, M.S.M. Colour removal from landfill leachate by coagulation and flocculation processes. Bioresource Technology, v.98, p.218-220, 2007

[20] NAGASHIMA, Lucila Akiko. Monitoramento de lixiviado em lagoa de estabilização e estudo da aplicabilidade do Reagente Fenton e do coagulante tanino como formas de tratamento. Tese (Doutorado em Engenharia Química) - Universidade Estadual de Maringá, Maringá, PR, 2009.

[21] PEDROSO, K., TAVARES, C.R.G, JANEIRO, V., SILVA, T.L., DIAS, P.Z., Avaliação do tratamento do lixiviado do aterro sanitário de Maringá, Paraná, por processo de coagulação/floculação com Tanfloc $S^{\circledR}{ }^{\circledR}$. Revista de Engenharia e Tecnologia, v. 4, No .2 , p. 8798, Ago/2012

[22] SEDLAK, R.I. Phosphorus and nitrogen removal from municipal wastewater, 2 ed. Ed. Chelsea, MI, Lewis Publishers, 1991.

[23] RIO GRANDE DO SUL, Secretaria do Meio Ambiente, Resolução Consema $n^{\circ}$ 128/2006, dispõe sobre a fixação de padrões de emissão de efluentes líquidos para fontes de emissão que lancem seus efluentes emáguas superficiais no estado do Rio Grande do Sul. 